\title{
Terminologia e tradução juramentada: questões de tipologia textual e equivalência terminológica interlinguística Português-francês-italiano
}

\author{
Lidia Almeida Barros \\ Maurizio Babini** \\ Francis Henrik Aubert ${ }^{* * * *}$
}

\begin{abstract}
RESUMO: Neste trabalho analisamos um conjunto de documentos traduzidos na modalidade juramentada de e para o português em relação aos idiomas francês e italiano. Objetivamos verificar a tipologia textual mais solicitada para a tradução juramentada nessas línguas e traçar um perfil da terminologia recorrente nesses tipos de textos. Apresentamos ainda exemplos de problemas de equivalência terminológica interlinguística que se manifestam quando se traduzem alguns dos tipos de textos pertencentes ao nosso corpus. Os dados aqui apresentados foram obtidos pelo projeto LexTraJu-O léxico da tradução juramentada, que desenvolve suas pesquisas na UNESP de São José do Rio Preto e objetiva obter subsídios para o aprimoramento dos Cursos de Tradução dessa instituição e dar uma contribuição aos estudos tradutológicos sobre o tema da tradução juramentada.
\end{abstract}

Palavras-chave: Terminologia; tradução juramentada; tipologia textual; equivalência terminológica interlinguística.

ABSTRACT: In this study we analyse a body of documents in sworn translation from and to Portuguese in relation to French and Italian. Our objective has been to check the textual typology most requested for sworn translation in these languages and to outline a profile of the terminology recurrent in these types of text. We also present examples of interlinguistic terminological equivalence which become apparent when one translates some of the types of text in our corpus. The data presented here was obtained by the LexTraJu-O lexical project of

Universidade Estadual Paulista de São José do Rio Preto. E-mail: lidia@ibilce.unesp.br.

** Universidade Estadual Paulista de São José do Rio Preto. E-mail: maurizio@ibilce.unesp.br.

*** Universidade de São Paulo - E-mail: fhaubert@usp.br. 
sworn translation, of which the research is developed in the São José do Rio Preto campus of UNESP with the objective of obtaining resources for the improvement of the Translation Courses of this institution and of making a contribution to translation studies on the theme of sworn translation.

Keywords: Terminology; sworn translation; textual typology; interlinguistic terminological equivalence.

\section{Introdução}

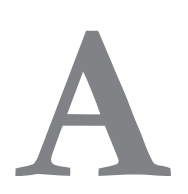

tradução juramentada (TJ) desempenha um papel de relevância nas relações comerciais, sociais e jurídicas internacionais do Brasil. Por conseguinte, o tradutor juramentado ${ }^{1}$ deve estar plenamente capacitado para bem desenvolver sua atividade profissional, visto a grande responsabilidade que carrega.

Por TJ entendemos "a tradução feita em formato apropriado para ter validade oficial e legal perante órgão em instituições públicas" (Andrart, 2004). No Brasil, toda documentação em língua estrangeira, para ter efeito legal, deve ser submetida ao processo de TJ; por esse motivo, o Código de Processo Civil reza, em seus Art. 156 e 157, que "só poderá ser junto aos autos documento redigido em língua estrangeira quando acompanhado de versão em vernáculo, firmada por tradutor juramentado". As instituições públicas de outros países também fazem exigências similares no que concerne a documentos brasileiros. Pessoas individualmente e empresas recorrem frequentemente à tradução juramentada de documentos particulares, societários e outros. A direção tradutória da TJ pode se dar tanto do idioma estrangeiro para o vernáculo como no sentido oposto.

No Brasil, em caso de processos judiciais, qualquer documento redigido originalmente em língua estrangeira é passível da exigência de tradução juramentada. Por exemplo, uma carta de amor deverá passar por esse procedimento se constituir uma prova em processo de divórcio; uma obra literária também pode se encontrar nessa situação em processos sobre direitos autorais.

No que concerne aos tipos de textos que frequentemente são submetidos à TJ, verificam-se diversidade e abrangência, ou seja, a gama de tipos de

A denominação oficial do profissional habilitado para efetuar traduções juramentadas no Brasil é tradutor público e intérprete comercial. Porém, por uma questão de agilidade na exposição dos dados, adotaremos, no âmbito deste trabalho, a denominação tradutor juramentado. 
textos com a qual os tradutores juramentados se deparam é vasta, impondo grandes exigências de competência por parte dos tradutores.

Neste trabalho analisaremos um conjunto de textos contidos em Livros de Registro de Traduções Juramentadas pertencentes a tradutores credenciados pela Junta Comercial do Estado de São Paulo para os idiomas francês e italiano (com traduções de e para o português). O objetivo é verificar a tipologia textual mais solicitada para a tradução juramentada relativa a essas línguas. Traçaremos, ainda, um perfil geral do conjunto terminológico predominante nesses tipos de textos e daremos exemplos de problemas de equivalência terminológica interlinguística com os quais os tradutores se deparam quando traduzem alguns dos tipos de textos encontrados em nosso corpus.

Os dados aqui apresentados consistem em resultados parciais obtidos nas pesquisas desenvolvidas na UNESP-Universidade Estadual Paulista no âmbito do projeto LexTraJu-O léxico da traducão juramentada ${ }^{2}$. Esses dados são fundamentais para que os Cursos de Tradução de nosso país possam preparar melhor os futuros tradutores.

2. Documentos mais frequentes em $\mathrm{TJ}$

De acordo com a experiência prática dos tradutores públicos e intérpretes comerciais, a maior parte dos documentos traduzidos sob a forma juramentada pode ser dividida nos seguintes grandes grupos:

a) documentos pessoais: carteira de identidade, certidões de nascimento, casamento, divórcio ou óbito; documentos escolares, carteiras de habilitação de motoristas, passaportes, e outros;

b) documentos societários: termos de incorporação, deliberações de conselhos de empresas, atas de reuniões, contratos em geral etc.

c) documentos financeiro-comerciais: balanços de empresas, faturas, notas de débito, letras de câmbio, conhecimentos de embarque, notas promissórias, correspondência comercial etc.

d) documentos legais: cartas rogatórias, atestados de antecedentes, procurações etc..

e) documentos de diferentes naturezas: patentes, transferência de tecnologia, correspondência eletrônica etc.

2 O LexTraju é financiado pela Fundação de Amparo à Pesquisa do Estado de São PauloFAPESP e pelo Conselho Nacional de Desenvolvimento Científico e Tecnológico-CNPq. 
Essas categorias de documentos abrangem uma gama tipológica textual tão vasta que fornecem apenas uma visão geral dos gêneros textuais com os quais o tradutor juramentado costuma se deparar. Essa generalização não auxilia, no entanto, no sentido de se identificarem as tipologias textuais mais solicitadas de acordo com as especificidades de cada idioma. De fato, nossas pesquisas têm demonstrado que as realidades do francês e do italiano são diferentes, ou melhor, para cada uma dessas línguas se apresentam tipos textuais que são, em parte, comuns às duas línguas e, em parte, diferentes, como veremos nos próximos itens deste trabalho.

Os documentos traduzidos são armazenados em Livros de "Registro de Traduções", que seguem normas de organização impostas pelas Juntas Comerciais dos estados brasileiros. Os tipos de textos traduzidos por um mesmo profissional podem variar de Livro para Livro, além de variar de tradutor para tradutor. Essas diferenças encontram-se diretamente relacionadas a uma série de elementos, dentre eles, o tempo de exercício na profissão por parte do tradutor público, fase de sua carreira, implantação no mercado, cidade em que atua, e outras.

Em determinado Livro pode predominar um tipo de documento, enquanto que, em outro Livro do mesmo tradutor, pode predominar outro tipo. Por esse motivo, consideramos os dados que apresentamos neste artigo como parciais, visto que se atêm a três Livros de cada língua (três de francês e três de italiano). Apesar dos limites impostos por esta pesquisa, alguns elementos generalizantes e importantes podem ser depreendidos.

\section{Tipologia textual francês-português mais frequente em TJ}

O Brasil mantém intensas relações com a França e outros países de língua oficial francesa. Assim, é natural que a TJ seja muito requisitada para que documentos oriundos desses países sejam aceitos oficialmente no Brasil e vice-versa.

Os três Livros de traduções juramentadas francês-português que analisamos compõem-se de 1200 páginas, contêm 49 tipos de documentos expressos em 185 exemplares na direção tradutória francês-português e 34 tipos de documentos que se concretizam em 176 exemplares na direção tradutória inversa. Assim, no total, 361 documentos traduzidos nas duas direções foram analisados.

Verificamos que os tipos de documentos mais solicitados para tradução do francês para o português são: reconhecimento de firma (19), certifi- 
cados diversos (18), atestados diversos (17), fax (15), certidão de registro de comércio (12). Esses são seguidos, em ordem decrescente, de certidões de nascimento e estatutos sociais (8 exemplares cada); atas de assembleias, contratos, diplomas e procurações (7 cada).

Com frequência menor encontramos as certidões de casamento, declarações e históricos escolares (4 cada); cartas diversas e atestados de antecedentes criminais (3 cada); boletins de ocorrência, carteiras de habilitação, certidões de batismo para casamento, certificações, delegações de assinatura, faturas, listas de candidatos, passaportes e cadernetas (livros) de família ${ }^{3}$ (2 cada). Os seguintes documentos possuem só um exemplar: apresentação de notícia de crime, apresentação de oferta pública, boletim de remissão, boletim escolar, carta de cobrança, certidão de divórcio, composição do capital social, conclusões enviadas ao Conseil de Prud'Hommes, convocação para comparecimento à Junta de Conciliação, créditos documentários, informações societárias, legalizações, mandado, notificação de despedida, parecer financeiro, pedido de medidas cautelares urgentes, petição, protocolo de declaração, recibo, relatório, resumo de assembleias, sentença de divórcio, subdelegação de poderes.

$\mathrm{Na}$ direção tradutória inversa, isto é, do português para o francês, observamos que os extraits d'acte de naissance destacam-se, em absoluto, em quantidade de exemplares: 38. Acreditamos que esse dado se apresente devido ao fato de que, na França (e em outros países da Europa), é comum a solicitação da certidão de nascimento a estrangeiros para diversas práticas administrativas de regulamentação de sua estada no país. De fato, na França, para se obter o permis de séjour, para montar o dossiê para fins de casamento e outros atos, um dos documentos solicitados é a certidão de nascimento.

Outros dois tipos de documentos que normalmente requisitam a tradução juramentada do português para o francês são os certificados e as declarações. Em nosso córpus encontramos 29 exemplares de certificados e 16 declarações. Esses são seguidos dos relevés de notes (12), passeports (11), actes de naissance (9), actes de mariage e diplômes (7 cada).

Os curriculum vitae e lettres (4 cada), actes de déclaration, carnet de vaccination, extrait d'acte de mariage, permis de conduire e pétition (3 cada), attestations, carnets de travail, commission rogatoire, mandat d'assignation et de notification e requêtes (2 cada) são, respectivamente, documentos que ocorrem com poucos exemplares.

3 Os nomes dos tipos de documentos foram aqui registrados literalmente como constam nos Livros de Registro de Traduções estudados, tanto em português quanto em francês e, mais adiante, em italiano. 
Somam-se a esses os seguintes tipos de documentos com um só exemplar: acte sous-seing privé, carte de certification d'enregistrement de professeur, carte de certification de traductrice assermentée, contrat de travail, décision, extrait de casier judiciaire, justificatif d'inscription, lettre de recommandation, ordonnance, plan de carrière, pouvoir, rapport d'expertise, transfert (scolaire), demande urgente d'effet suspensif.

4. Tipologia textual italiano-português mais frequente em TJ

O Brasil também mantém intensas relações com a Itália há muito tempo, principalmente devido à imigração de cidadãos daquele país para o Brasil no final do século XIX e início do século XX. A situação inversa também liga esses dois países: onda de emigração de brasileiros para a Itália, composta, normalmente, de descendentes de imigrantes italianos, ocorrida nos últimos 20 anos. Assim, é natural que a TJ seja muito requisitada para que documentos oriundos desse país sejam aceitos oficialmente no Brasil e na Itália.

Os três Livros de traduções juramentadas italiano-português que analisamos compõem-se de 1200 páginas, contêm 24 tipos de documentos expressos em 86 exemplares na direção tradutória italiano-português e 34 tipos de documentos que se concretizam em 465 exemplares na direção tradutória inversa. Assim, no total, 551 documentos traduzidos nas duas direções foram analisados.

Verificamos que os tipos de documentos mais solicitados para tradução do italiano para o português são, nos livros analisados: artigo de jornal/ revista (11), certidão de nascimento (10), procuração (8), certidão de casamento e cartas em geral (6 cada).

Esses são seguidos, em ordem decrescente, de encarte publicitário, declaração e atestado de antecedentes (4 cada), histórico escolar, estatuto social, e-mail, certificado de residência, nacionalidade e estado civil, certificado de residencia e certificado (de modo geral) (3 cada); passaporte, imposto de renda, diploma, boletim de ocorrência, apólice de seguro (2 cada); comunicação interna, certidão de registro de comércio, certidão de processos em andamento, atestado de residência, atestado de estado civil (1 cada).

Salta aos olhos a quantidade de traduções na direção português'!italiano dos certificati di nascita - 160 exemplares. Seguem, ainda, em grande quantidade, os certificati di matrimonio (70), certificati di morte (53), articoli di giornale/ rivista (31), certificati di esonero dal servizio di leva (22), percorsi della vita accademica (18), rogatoria internazionale(16), certificati (11), certificati negativi di naturalizzazione (11) e certificati di conclusione (10).

Em menor quantidade, encontramos os seguintes documentos: procura (7), diploma e petizione iniziale (6 cada); denuncia del pubblico ministero e parere legale 
(4); denunci, estratto dell'atto di nascita e rapporto medico (3 cada); certificato riassuntivo, decisione (2), domande suggerite per interrogatorio, estratti conto, interrogatorio, ordine di citazione e d'intimazione, ricorso e verbale di dichiarazioni (2 cada).

Onze tipos de documentos apresentaram-se com exemplares únicos, a saber: atto di rimozione dei sigilli, certificato d'iscrizione alla riserva, certificato del casellario giudiziale, certificato di riservista, certificato penale del casellario gindiziale, divorzio consensuale, lettere di lettori, ordine di notificazione, presentazione del consiglio di amministrazione, scrittura di dichiarazione e spiegazione dal giudice.

5. Breve perfil da terminologia recorrente no corpus

A tipologia textual exerce uma influência decisiva sobre o perfil da terminologia encontrada nos documentos analisados. Assim, tanto no italiano quanto no francês, o corpus apresenta uma grande quantidade de documentos pessoais, escolares, jurídicos e empresariais. Analisando a terminologia encontrada nesses documentos, podemos chegar ao seguinte perfil geral:

- A grande maioria dos termos apresenta-se sob a forma de unidades linguísticas plenamente articuladas (formadas apenas por letras), encontrando-se poucos símbolos ou outras formas de designação de um conceito. Mesmo nos documentos empresariais predomina esse tipo de unidade terminológica (em forma totalmente linguística), diferentemente do que ocorre em balanços de empresas, conhecimentos de embarque e outros tipos de documentos frequentemente solicitados à tradução juramentada português-inglês, por exemplo, nos quais se verifica uma enorme quantidade de conceitos designados por formas não-linguísticas (símbolos e outros).

- Termos próprios do tipo de documento traduzido: ex.: contratante, contratado, para contratos; certidão de nascimento, certidão de casamento, diploma, boletim de ocorrência e outros, que, em geral, aparecem como denominação do tipo de documento traduzido.

- Termos jurídicos: a quantidade considerável de documentos de cunho jurídico e mesmo pessoais com caráter legal (certidões e outros) faz com que o tradutor desses tipos de textos se defronte com uma terminologia altamente consolidada e específica do domínio jurídico. Em nosso corpus, predomina uma terminologia do Direito Civil e Criminal, encontrando-se menos termos ligados ao Direito Comercial, embora estes também estejam presentes nos 
estatutos sociais, atas de assembleias de associados, contratos e outros tipos de documentos.

- Nomes próprios: o grande volume de documentos pessoais e escolares, além de procurações e de processos judiciais, faz com que a quantidade de nomes próprios seja considerável. Encontramse, dentre eles, antropônimos e topônimos, uma vez que nesses documentos, e mesmo nos societários, encontram-se nomes das pessoas envolvidas, nomes das repartições públicas ou empresariais, logradouros e outros.

- Termos culturalmente marcados: a presença marcante de nomes próprios ligados às denominações das repartições públicas brasileiras, francesas e italianas faz com que a tradução se defronte com aspectos da organização social de um dos países envolvidos que, nem sempre, encontram correspondentes exatos nos outros países. Essas diferenças e particularidades de realidade extralinguística acarretam, evidentemente, consequências sobre a expressão linguística. Assim, encontra-se, no corpus analisado, uma quantidade considerável de termos culturalmente marcados, o que impõe problemas no que concerne à busca de equivalentes terminológicos interlinguísticos. Essas questões serão abordadas com mais detalhes adiante.

- Termos e fraseologismos relativos à própria TJ: Por fim, encontramos no corpus analisado um reduzido conjunto de termos e de fraseologismos sempre utilizados na tradução na modalidade juramentada. Ex.: tradução juramentada, emolumentos, certifico e dou fé, e outros. A maior parte dos fraseologismos encontrados é, porém, de uso frequente do discurso cartorial, não sendo, portanto, exclusivo da tradução juramentada.

Estas seriam, portanto, as principais características da terminologia predominante no corpus analisado e as observações são válidas para as traduções em ambas as direções (português ${ }^{\circledR}$ língua estrangeira e vice-versa) e para as línguas envolvidas em nosso estudo.

6. Questões de equivalência terminológica interlinguística

O profissional da tradução, ao traduzir os documentos encontrados em nosso corpus, depara-se com dificuldades de encontrar equivalência terminológica perfeita de termos que são culturalmente marcados. Por equiva- 
lência (dita) perfeita entendemos, com Dubuc (1985), aquela em que o termo da língua A recobre o mesmo conceito, possui os mesmos usos e se situa no mesmo nível de língua do termo da língua $B$. As diferenças que regem as distintas realidades extralinguísticas provocam, na maioria das vezes, as dificuldades de identificação de equivalentes (ditos) perfeitos. Assim, aspectos linguísticos só podem ser entendidos e dificuldades solucionadas à luz de uma análise de aspectos socioculturais que envolvem as línguas e os respectivos países de origem dos documentos traduzidos.

A ausência de equivalência pode ocorrer com frequência com os termos do discurso cartorial, visto que esses expressam a realidade do país e nem sempre dois países estão fundamentados nas mesmas leis ou possuem as mesmas práticas. Um exemplo de termo encontrado no corpus em francês e que normalmente proporciona dificuldade de identificação de equivalentes é reconbecimento de firma ${ }^{4}$. Sua definição é:

Ato notarial, com validade iuris tantum, pelo qual o tabelião atesta, no próprio documento, que a assinatura nele constante é de quem a lançou, segundo confrontação com o autógrafo existente em suas notas. Prática dispensada nos documentos que tramitam pela administração pública federal, direta ou indireta. (Sidou, 2004)

Em nosso corpus, reconbecimento de firma é a denominação atribuída pelo tradutor ao tipo de documento que lhe foi confiado para a tradução juramentada, porém esse termo também foi encontrado em textos de alguns documentos traduzidos, como podemos verificar no excerto a seguir, extraído de uma tradução juramentada de contrato que faz parte do corpus analisado.

A CONTRATANTE reembolsará à CONTRATADA o custo de todos os materiais utilizados na execução dos serviços ora ajustados, tais como formulários contínuos, impressos fiscais, trabalhistas e contábeis, bem como livros fiscais, pastas, cópias reprográficas, autenticações, reconhecimento de fir$\mathrm{mas}^{5}$, custas, emolumentos e taxas exigidas pelos serviços públicos, sempre que utilizados e mediante recibo discriminado acompanhado dos respectivos comprovantes de desembolso.

O reconhecimento de firma é um procedimento exigido pela legislação brasileira para comprovar a veracidade da assinatura de uma pessoa.

4 Os dados referentes a este exemplo foram extraídos da Dissertação de Mestrado de Gildaris Ferreira Pandim (Pandim, 2007: 114-15), membro de nossa equipe de pesquisa no projeto LexTraJu.

5 Grifo nosso. 
Outros países, como a França e a Itália, não prevêem esse procedimento. Assim, apresenta-se um problema de tradução. Ao analisar os documentos de nosso corpus e ao tentar identificar um possível equivalente para reconhecimento de firma, acreditamos, inicialmente, que pudesse ser vérification d'écriture, que, em francês, significa

Def.: procédure qui a pour objet de faire reconnaitre par le juge que l'écriture ou la signature d'un acte sous seing privé émanent de la personne à qui on l'attribue. (Cornu, 2002)

Legislação : Article 1324 (Loi no 2000-230 du 14 mars 2000 art. 1 Journal Officiel du 14 mars 2000). Dans le cas où la partie désavoue son écriture ou sa signature, et dans le cas où ses héritiers ou ayants cause déclarent ne les point connaitre, la vérification en est ordonnée en justice. (França, 2004)

Diante do exposto, podemos compreender que o processo de vérification d'écriture pode ser feito para reconhecer a assinatura de uma pessoa quando pairam dúvidas sobre ela. Seria, na verdade, para reconhecer a letra da pessoa. Para este caso em específico, temos, em português, o termo reconhecimento de letra:

Def.: afirmação como autêntico, por agente público, de manuscrito. OBS. O reconhecimento de letra se faz inseparavelmente do reconbecimento de firma, ou assinatura. (Sidou, 2004)

Ocorre, porém, que o reconhecimento de firma é feito, no Brasil, no cartório, é um ato notarial, que pode servir para fins múltiplos. Já na França, vérification d'écriture é um processo feito somente em Justiça, quando há algum problema com a assinatura da pessoa.

Há, portanto, uma ausência de equivalência em francês para reconbecimento de firma, visto que o recorte das realidades francesa e brasileira são diferentes. No Brasil, a pessoa tem que provar que a assinatura é realmente sua, enquanto que, na França, a pessoa é, a priori, "dona" daquela assinatura e não precisa atestar sua veracidade. A verificação só é feita em caso de dúvidas ou denúncias.

Teríamos, então, em português, dois termos, um para designar reconhecimento de firma e outro para designar reconbecimento de letra, enquanto que, em francês, teríamos apenas o termo vérification d'écriture como equivalente deste último e ausência de equivalência para reconbecimento de firma.

Analisando os documentos de reconhecimento de firma que constam do corpus, verificamos que se tratava de uma exigência brasileira a documentos vindos de outros países e que deixavam o titular da assinatura inclusive 
em situação desagradável. De fato, como esse procedimento não é comum em outros países, a pessoa é obrigada a se dirigir a tabelião, que, muitas vezes, fica desconfiado desse tipo de solicitação. Uma prova dessa situação são os textos inseridos ao lado da comprovação da assinatura, inserções feitas pelo tabeliães franceses:

Eu, abaixo assinado, Dr. XXXXX, tabelião em Paris, reconheço como autêntica a assinatura do Sr. YYYYY, aposta acima, após apresentação da CNI [carteira nacional de identidade] $\mathrm{n}^{\circ} 000000000$, expedida em 00 de setembro de 0000, pela "Prefeitura de Polícia", Paris, [dados ilegíveis] (75), sem nenhuma certificação do conteúdo nem dos efeitos do presente documento ${ }^{6}$.

Dr. XXXXX, Tabelião em Paris, certifica somente a materialidade da assinatura do Sr. YYYYYY, aposta ao lado. Este reconhecimento de assinatura não pode, em caso algum, conferir ao presente documento caráter de um instrumento notarial; a responsabilidade do Tabelião não pode, a nenhum título, ser questionada no que se refere ao conteúdo do presente documento ${ }^{7}$.

Assim, evidencia-se a estranheza - e a respectiva preocupação - que causa nos tabeliães franceses uma solicitação de reconhecimento de firma. Comprova-se, desse modo, a não-correspondência de realidades extralinguísticas e socioculturais, que se reflete na esfera linguístico-terminológica. Esse fenômeno é comum na área jurídica, já que as leis possuem particularidades em cada país.

Outro exemplo interessante de dificuldade de equivalência terminológica interlinguística dá-se entre o português e o italiano. Comparando-se o sistema escolar brasileiro e a documentação que acompanha o desempenho do aluno na escola e seus homólogos na Itália, verificamos que há algumas diferenças, o que dificulta a identificação de equivalentes perfeitos portuguêsitaliano para determinados termos. Um exemplo é o caso do termo histórico escolar em português.

O histórico escolar brasileiro é o "registro das atividades curriculares realizadas pelo discente e pode ser parcial (enquanto estiver regular) ou final (após a conclusão ou desligamento do curso)" (Ciac-Ufpa, 2009). Em italiano, encontramos duas realidades linguísticas diferentes para designar esse conceito, essa distinção ocorrendo se nos referirmos à escola até o Ensino Médio ${ }^{8}$

6 Alguns dados foram aqui omitidos por uma questão de confidencialidade. Grifos nossos.

7 Idem.

8 Quando falamos em Ensino Médio, referimo-nos ao Brasil. No lado italiano, estamos, de modo subentendido, referindo-nos à Scuola Superiore. 
ou à Universidade. De fato, na Itália, até o final do Ensino Médio o único documento que registra notas, ausências e qualquer outro tipo de avaliação do aluno é a pagella, que podemos definir como:

Documento escolar no qual são registradas as notas e a avaliação que o aluno obteve nas várias disciplinas durante o trimestre ou o quadrimestre, ou nos exames: faz̧er o pai assinar a $p . / /$ por ext. Conjunto de avaliações registradas na pagella: ter uma boa, uma má p. (Hoelpli.it, 2009)9

Analisando o conteúdo conceptual do termo pagella, percebemos que pode ser considerado como equivalente - se não perfeito, quase que perfeito - do boletim escolar brasileiro. Pagella não corresponde, no entanto, ao histórico escolar emitido pelas escolas brasileiras em todos os níveis, que revela o resultado das aprovações e percentual de frequência às aulas de um aluno ao final de um curso. O histórico escolar também pode ser emitido anualmente, contendo o resultado das disciplinas cursadas até então e as respectivas avaliações.

Consultamos a escola ítalo-brasileira de São Paulo, Scuola Italiana Eugenio Montale, e autoridades italianas que lidam com documentos escolares e constatamos que, para a escola até o fim do Ensino Médio, não existe um documento que possa se equiparar ao histórico escolar brasileiro. Quando é necessário matricular o aluno na série escolar subsequente, solicita-se a última pagella ou todas as pagelle emitidas até então. Para fins de transferência, a escola de origem emite o documento Nulla Osta, isto é, o comprovante de que o aluno não se encontra com nenhuma pendência acadêmica e que foi aprovado no ano anterior, podendo, portanto, matricular-se no ano escolar solicitado.

Por outro lado, na Itália, quando se trata de Universidade (ou cursos de nível superior) existe o Certificato degli esami, que pode ser assim definido:

O "certificado de exames" (Transcript of Records) documenta o aproveitamento de um aluno, registrando a lista de disciplinas cursadas, os créditos obtidos, assim como as notas locais e possivelmente as notas ECTS atribuídos. ${ }^{10}$ (Cmgt, 2009)

9 Documento scolastico sul quale sono segnati i voti o i giudizi che l'alunno ha ottenuto nelle varie materie durante i trimestri o quadrimestri, o agli esami: far firmare al padre la $p . /$ / estens. Complesso delle valutazioni segnate sulla pagella: avere una buona, una cattiva $p$. (Tradução nossa).

10 Tradução nossa do texto original: Il certificato degli esami (Transcript of Records) documenta il profitto di uno studente riportando l'elenco dei corsi seguiti, i crediti ottenuti nonché i voti locali e possibilmente i voti ECTS attribuiti. 
Comparando o conteúdo conceptual do termo Certificato degli esami e do histórico escolar, observamos que ambos possuem uma larga zona de intersecção semântica e pragmática, e que, ao que tudo indica, podem ser considerados como equivalentes terminológicos quando se referem aos documentos emitidos por instituições de ensino superior (IES).

Desse modo, teríamos, para a escola até o final do Nível Médio e para a Universidade, a seguinte situação de equivalência entre os termos em português e em italiano:

\begin{tabular}{|c|c|}
\hline $\begin{array}{c}\text { Português: até o final do } \\
\text { ensino Médio }\end{array}$ & $\begin{array}{c}\text { Italiano: até finaldo ensino } \\
\text { médio (Scuola Superiore) }\end{array}$ \\
\hline Boletim escolar & pagella \\
\hline Histórico escolar & $\varnothing$ \\
\hline
\end{tabular}

Quadro 5 : Equivalências de boletim escolar e histórico escolar no Ensino Médio

\begin{tabular}{|c|c|}
\hline $\begin{array}{c}\text { Português: nível } \\
\text { Superior (ies) }\end{array}$ & $\begin{array}{c}\text { Italiano: Nível } \\
\text { Superior (ies) }\end{array}$ \\
\hline (Boletim escolar) $\varnothing$ & (Boletim escolar) $\varnothing$ \\
\hline Histórico escolar & Certificato degli esami \\
\hline
\end{tabular}

Quadro 6 : Equivalências de boletim escolar e histórico escolar no Ensino Superior

Desse modo, verificamos que o boletim escolar existe tanto no Brasil quanto na Itália para registrar a avaliação dos alunos da escola até o final do Ensino Médio. Caso tradutores brasileiros ou italianos tenham que buscar os equivalentes nessas línguas para boletim escolar, tratando-se de documento emitido nas escolas até o final do Nível Médio, não encontrarão problema e poderão indicar, tranquilamente, como equivalentes terminológicos boletim escolar $=$ pagella .

Em ambos os países não existe, porém, boletim escolar no Nível Superior, o que faz com que o tradutor nunca tenha que se deparar com o problema de buscar um equivalente de boletim escolar em português ou em italiano quando se tratar de documentação de alunos de Cursos de Nível Superior.

Por outro lado, os tradutores brasileiros que tiverem que buscar, em italiano, um equivalente terminológico para designar o que, no Ensino Médio 
no Brasil, é o histórico escolar, terão problemas, visto que esse tipo de documento não existe na Itália nas escolas de nível anterior à Universidade. Nesta última, porém, é normal, tanto na Itália quanto no Brasil, emitir-se um documento contendo o conjunto de disciplinas estudadas pelo aluno e as avaliações obtidas, que se chamam, respectivamente, certificato degli esami e histórico escolar. Pode-se, então, considerar esses termos como equivalentes.

O problema para o tradutor se coloca, então, quando deve encontrar um equivalente em italiano para o termo, em português, histórico escolar, quando este designa o documento emitido nas escolas até o final do Ensino Médio. A pesquisa terminológica sobre um possível equivalente em italiano conclui-se indicando uma ausência de equivalente perfeito, mas um eventual equivalente funcional poderia ser certificato degli esami. Assim, o tradutor, na ausência de um termo específico, mas de posse de um que designa o mesmo conceito, mas que não possui normalmente o mesmo uso (e, portanto, considerado como equivalente parcial), pode optar por essa solução tradutória. Essa é uma prerrogativa do tradutor diante de vazios completos ou parciais de equivalência.

\section{Conclusão}

Nossa investigação científica se deu sobre um corpus composto de três Livros de Registro de Traduções de Traduções Juramentadas de e para o português em relação às línguas francesa e italiana. No total, 144 tipos de textos envolvendo 912 documentos foram analisados e a terminologia encontrada nesses documentos foi estudada.

Observamos que, na direção tradutória francês'!português predominam os documentos comerciais e legais/cartoriais, tais como reconhecimento de firma (19), certidão de registro de comércio (12), estatutos sociais (8); atas de assembleia, contratos e procuracões (7 cada). Dentre os atestados (17) e fax (15), muitos dizem respeito a atividades profissionais e outros a atividades comerciais.

$\mathrm{Na}$ direção tradutória inversa (português'!francês), dos 20 tipos de textos mais frequentes, 11 são de cunho pessoal, quatro são legais e três (certificados, declarações e cartas) se referem a questões pessoais ou comerciais. Boa parte desses documentos se relaciona a trabalho, possivelmente de pessoas que têm intenção de exercer, na França, alguma atividade remunerada (certificados e declarações de que pessoas concluíram determinados cursos e estão capacitados para desenvolver esta ou aquela atividade profissional, cartas de recomendação, e outras). 
Esses dados talvez evidenciem que, na direção França'!Brasil, predomine uma relação comercial-societária, enquanto que, na direção inversa, dêse uma relação mais pessoal, mais de interesse individual de brasileiros para fins diversos (estudo, casamento e outros). Mesmo os documentos relacionados a atividades remuneradas (trabalho) não se caracterizam como de tipo societário. Os documentos jurídico/legais/cartoriais têm presença marcante nas duas direções tradutórias, como expressão de processos sobre crimes, divórcios, pensões alimentícias e para reconhecimento de firmas ou procurações.

No que tange ao italiano, na direção tradutória italiano!!português, predominam os documentos pessoais, mas encontramos alguns documentos comerciais e jurídicos. É interessante observar que em um dos Livros de Registro de Tradução do italiano constavam vários artigos de revista e encartes publicitários. Perguntamo-nos por que alguém teria necessidade de traduzir textos dessa natureza sob a forma juramentada. Consultamos, então, esses documentos e verificamos que se tratam de reportagens ou propagandas da Parmalat, que, na época, vivia o escândalo da falência. Assim, pessoas e sociedades comerciais brasileiras que se sentiram lesadas pela falência da Parmalat entraram com processos na Justiça e utilizaram esses artigos e encartes publicitários como provas documentais. Esse caso confirma o que os tradutores juramentados sempre afirmaram: que qualquer texto pode ser passível de tradução juramentada.

Dentre os documentos traduzidos do português'!italiano não há praticamente nenhum documento de tipo puramente comercial. Encontramos um número elevado de documentos de cunho pessoal e jurídico. A maior parte destes últimos deve-se a processos contra brasileiros e italianos que cometeram crimes financeiros e se refugiaram ou depositaram divisas na Itália ou no Brasil. As procurações são duas: uma pessoal e outra para fins comerciais.

No que concerne aos documentos pessoais, esses se destacam, de longe, em número de exemplares. De fato, 355 documentos, ou seja, cerca de $76 \%$ dos exemplares traduzidos do português para o italiano são de cunho pessoal. Uma explicação para esse quadro muito provavelmente repouse no interesse por emigração de brasileiros para a Itália e por obtenção da cidadania italiana.

Comparando os documentos traduzidos do francês e do italiano para o português, observamos a existência de tipos comuns às duas línguas, a saber: atestado de antecedentes, boletim de ocorrência, cartas (pessoais e comerciais), certidão de casamento, certidão de nascimento, certidão de registro de comércio, certificados (di- 
versos), declaração, diploma, estatuto social, histórico escolar e passaporte. Dentre os documentos traduzidos do português para essas línguas, são comuns (ao francês e ao italiano) os seguintes tipos de textos: Atestado de antecedentes, Certidão de casamento, Certidão de nascimento, Certificados (diversos), Decisão, Diploma, Extrato de certidão de nascimento, Histórico escolar, Petição e Procuração. Independentemente da direção tradutória, temos, como documentos comuns entre o italiano e o francês: Atestado de antecedentes, Certidão de casamento, Certidão de nascimento, Certificados (diversos), Diploma e Histórico escolar.

Esses dados são relevantes, na medida em que nossa pesquisa objetiva identificar os tipos textuais mais frequentemente submetidos à tradução juramentada para, com esses subsídios, podermos elaborar ferramentas que atendam às necessidades dos tradutores juramentados, auxiliando-os, assim, a garantir maior precisão a seu trabalho.

Analisando a terminologia encontrada nos documentos traduzidos do português para o francês e para o italiano, e os documentos traduzidos na direção contrária que compõem nosso corpus de análise, pudemos chegar ao seguinte perfil geral: 1) a grande maioria dos termos apresenta-se sob a forma de unidades linguísticas plenamente articuladas (formadas apenas por letras); 2) ocorrem muitos termos inerentes ao tipo de documento traduzido: ex.: contratante, contratado, para contratos, e outros, muitos sendo, inclusive, denominação do tipo de documento traduzido; 3) presença marcante de termos jurídicos, sobretudo do Direito Civil e Criminal; 4) forte presença de nomes próprios (antropônimos e topônimos); 5) grande ocorrência de termos culturalmente marcados. 6) termos e expressões de uso próprio da tradução juramentada são praticamente inexistentes: alguns termos e expressões são muito utilizados, mas não de uso exclusivo da TJ, sendo frequentes no discurso cartorial.

Devido a essas particularidades da terminologia encontrada nos documentos analisados, nem sempre é possível identificar equivalentes perfeitos (ou totais) para os termos estudados. De fato, muitas vezes isso é possível, mas também há casos em que se apresenta ausência de referencial semânticoconceptual e pragmático em uma das línguas e, por conseguinte, ausência de equivalente terminológico. Há ainda situações em que é possível propor um equivalente parcial para o preenchimento de uma lacuna de equivalência perfeita, assim o termo proposto seria um equivalente funcional. Nessas situações, nem sempre a perda é muito grande, visto que o equivalente proposto recobre razoavelmente a significação do termo da língua de partida. Assim, frequentemente, esse recobrimento semântico-conceptual, embora não seja perfeito, é suficiente para dar conta das necessidades tradutórias. 
Evidencia-se que as diferenças que pairam sobre o léxico de documentos escolares brasileiros e italianos advêm das diferenças das estruturas organizacionais do sistema educacional e dos documentos escolares desses países. Desse modo, questões de equivalência terminológica interlinguística constituem a expressão de diferenças e semelhanças de realidades socioculturais.

Todas essas observações revelam algumas tendências, porém restringem-se aos dados de três Livros de Registro de Traduções de cada língua. Somente um estudo mais aprofundado da tipologia textual de outros Livros e de outros tradutores nos permitirá fazer afirmações mais categóricas. Por isso, daremos continuidade às nossas pesquisas no âmbito do LexTraJu.

\section{Referências bibliográficas}

ANDRART. O que é uma tradução juramentada. Disponível em: http://www.andrart.com/ portugues/faq_br.html. Acesso em 15.03.2004.

BARROS, L. A.; AUBERT, F. H.; CAMARGO, D. C. de. 2008. Terminologie et typologie textuelle: une contribution à l'étude de la traduction assermentée français-portugais. In: MANIEZ, F.; DURY, P. (org.). Lexicographie et terminologie: histoire de mots. Lyon: Presses Universitaires de Lyon. p. 347-56.

CIAC-Centro de Registro e Indicadores Acadêmicos. UFPA-Universidade Federal do Pará. Disponível em: http://www.ufpa.br/ciac/index.php?option=com_content\&view=article \&id $=86$ : historico-escolar\&catid $=35$ : servicos\&Itemid $=70$. Acesso em 21.05.2009.

CMGT-CONSERVATORIO DI MUSICA GIUSEPPE TARTINI. Certificato degli esami (ToR). Disponível em: http://www.conservatorio.trieste.it/cooperazione-internazionale/ ects/certificato-degli-esami-tor. Acesso em 21.05.2009.

CORNU, G. 2002. Vocabulaire juridique. Paris: Quadrige.

DUBUC, R. 1985. Manuel pratique de terminologie. 2è éd. Québec: Linguatech.

FRANÇA. 2004. Code civil. Paris: Dalloz.

HOELPLI.it. La Grande Libreria Ondine. Disponível em: http://dizionari.hoepli.it/ Dizionario_Italiano/cerca.asp $x$ ? $i d D=1 \& q u e r y=$ pagella@ $\&$ erca. $x=27 \&$ Cerca. $y=8$. Acesso em 21.05.2009.

PANDIM, G. F. 2007. Questões comparadas do léxico da tradução juramentada de contratos de prestação de serviços português-francês. Dissertação (Mestrado). Universidade Estadual Paulista, câmpus de São José do Rio Preto.

SCHMIED, V. S. 2007. O léxico da tradução juramentada de históricos escolares em português e em italiano. Relatório de Iniciação Científica apresentado ao Instituto de Biociências, Letras e Ciências Exatas da Universidade Estadual Paulista, Câmpus de São José do Rio Preto. Orientador: Prof ${ }^{a}$. Dr ${ }^{a}$. Lidia Almeida Barros. Bolsa CNPq/PIBIC.

SIDOU, J. M.O. 2004. Dicionário Jurídico. Rio de Janeiro: Forense Universitária. 